\title{
Prevalence of Vitamin B12 Deficiency and its Associated Factors among Patients with Type 2 Diabetes Mellitus on Metformin from a District in Malaysia
}

\author{
Gayathri Devi Krishnan, ${ }^{1}$ Miza Hiryanti Zakaria, ${ }^{2}$ Norhayati Yahaya ${ }^{1}$ \\ ${ }^{1}$ Hospital Raja Perempuan Zainab II, Kota Bharu, Kelantan, Malaysia \\ ${ }^{2}$ Hospital Tengku Ampuan Afzan, Kuantan, Pahang, Malaysia
}

\begin{abstract}
Introduction. Vitamin B12 deficiency is more common among metformin-treated subjects although the prevalence is variable. Many factors have been associated with this. The aim of this study is to determine the prevalence of vitamin B12 deficiency and its associated factors among patients with type 2 diabetes mellitus (DM) who are on metformin.

Methodology. A total of 205 patients who fit eligibility criteria were included in the study. A questionnaire was completed, and blood was drawn to study vitamin B12 levels. Vitamin B12 deficiency was defined as serum B12 level of $\leq 300 \mathrm{pg} /$ $\mathrm{mL}(221 \mathrm{pmol} / \mathrm{L})$.

Results. The prevalence of vitamin B12 deficiency among metformin-treated patients with type 2 DM patients was $28.3 \%(n=58)$. The median vitamin B12 level was $419( \pm 257) \mathrm{pg} / \mathrm{mL}$. The non-Malay population was at a higher risk for metformin-associated vitamin B12 deficiency [adjusted odds ratio (OR) 3.86, 95\% Cl: 1.836 to 8.104 , p<0.001]. Duration of metformin use of more than five years showed increased risk for metformin-associated vitamin B12 deficiency (adjusted OR 2.06, 95\% Cl: 1.003 to $4.227, p=0.049$ ).

Conclusion. Our study suggests that the prevalence of vitamin B12 deficiency among patients with type 2 diabetes mellitus on metformin in our population is substantial. This is more frequent among the non-Malay population and those who have been on metformin for more than five years.
\end{abstract}

Key words: Vitamin B12, metformin, deficiency, type 2 diabetes mellitus, type 2 DM

\section{INTRODUCTION}

Type 2 diabetes mellitus is a major non-communicable disease in Malaysia for which metformin is one of the most commonly prescribed first line medications. Multiple cross-sectional studies have reported a wide range in prevalence of biochemical vitamin B12 deficiency with metformin exposure, ranging from $5.8 \%$ to as high as $30 \%{ }^{1-5}$ Vitamin B12 deficiency associated with metformin use is thought to occur due to vitamin B12 malabsorption at the terminal ileum..$^{5-7}$

Vitamin B12 deficiency is clinically important as it is a reversible cause of bone marrow failure and nerve damage. ${ }^{8}$ Neurological damage as a result of metformininduced vitamin B12 deficiency can present as peripheral neuropathy and may be mistaken for diabetic neuropathy. ${ }^{8}$ Because vitamin B12 deficiency and its associated complications are treatable and potentially reversible,

ISSN 0857-1074 (Print) I eISSN 2308-118x (Online)

Printed in the Philippines

Copyright (C) 2020 by Krishnan et al.

Received: April 4, 2020. Accepted: August 7, 2020.

Published online first: August 25, 2020.

https://doi.org/10.15605/jafes.035.02.03 early detection and treatment are clinically important in patients with diabetes who are on metformin. ${ }^{9}$

The first large scale study among Asians designed to investigate the prevalence and risk factors associated with vitamin B12 deficiency was conducted among Koreans in 2014. It reported vitamin B12 deficiency in 9.5\% of the patients who were on metformin. ${ }^{9}$ Interestingly, another study among the South African population demonstrated that subjects of black South African descent on metformin had a lower prevalence of B12 deficiency, suggesting that different ethnic origins may influence the prevalence of metformin-associated vitamin B12 deficiency. ${ }^{10}$ This study is the first of its kind that investigated the association between ethnicity and vitamin B12 deficiency among metformin-treated type $2 \mathrm{DM}$ patients.

Duration of use and dose of metformin have also been shown to influence vitamin B12 levels. A meta-analysis of six randomized controlled trials showed a significant

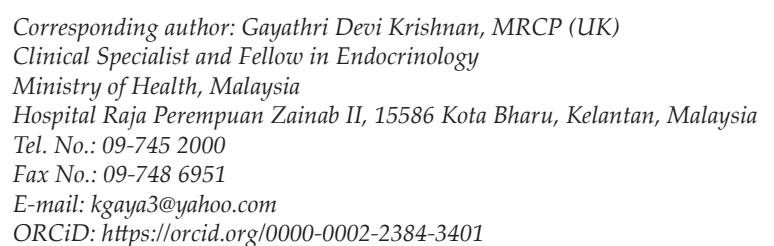


reduction in vitamin B12 levels induced by metformin and suggested that this may be dose dependent. ${ }^{11}$ In another large study published in the same year, Korean patients on higher doses (metformin $>1 \mathrm{~g}$ daily) and with longer treatment duration ( $>4$ years) were more likely to be deficient in vitamin B12. ${ }^{9}$

Some studies have found lower serum levels of vitamin B12 in smokers, but the exact mechanism for this is still poorly understood. ${ }^{12}$ It is thought that smokers generally have poor dietary intake. The second National Health and Nutrition Survey (NHANES II) found that smokers have a lower intake of most vitamins and were less likely to have consumed fruit, vegetables, vitamins and mineral supplements. Proton pump inhibitors (PPI) and histamine 2 receptor antagonists $\left(\mathrm{H}_{2} \mathrm{RA}\right)$ may lead to malabsorption of vitamin B12 due to inhibition of gastric acid secretion and reduced production of the intrinsic factor. ${ }^{13}$ Excessive alcohol intake is also linked to vitamin B12 deficiency. This has been attributed to intestinal malabsorption due to altered binding of intrinsic factor and alcoholinduced ileal damage. ${ }^{10,14}$

The primary objective of this study is to determine the prevalence of vitamin B12 deficiency among patients with type $2 \mathrm{DM}$ who are on metformin in Malaysia. Our secondary objective is to determine the associated factors contributing to vitamin B12 deficiency in this cohort.

\section{METHODOLOGY}

\section{Study Population}

This was a cross-sectional prevalence study. A total of 252 patients with type 2 DM were screened from two study centers in the district of Kuantan, Pahang in Malaysia. Patients who turned up for their scheduled clinic appointment at the type 2 diabetes clinic in the two centers were seen screened and recruited during their routine clinic visit between September 2018 and February 2019. Patients aged 18 years old and above with a diagnosis of type $2 \mathrm{DM}$ who were on metformin for at least 6 preceding months were screened. Participants were recruited based on eligibility and willingness to participate. Forty-six patients were excluded based on the exclusion criteria, while one declined to join. Patients who had pernicious anaemia; prior bariatric surgery, gastrectomy, colectomy or inflammatory bowel disease; ongoing critical illnesses; malignancy; liver cirrhosis or renal impairment (creatinine $\geq 265 \mu \mathrm{mol} / \mathrm{L}$ ) were excluded. Subjects who were vegetarians, recipients of vitamin B12 injections or supplements within the past 3 months, pregnant or lactating were excluded as well. Once informed consent was obtained, all participants were interviewed based on a standardized questionnaire (Appendix 1). Blood extraction for serum vitamin B12 levels was done. Vitamin B12 deficiency was defined as serum B12 level $\leq 300 \mathrm{pg} / \mathrm{mL}$ (221 $\mathrm{pmol} / \mathrm{L})$. This encompasses vitamin B12 levels defined as low and borderline low. ${ }^{3,9,15}$ Serum vitamin B12 level was measured by chemiluminescent microparticle Intrinsic Factor assay using the 7K61 ARCHITECT B12 Reagent Kit.

Sample size was calculated based on the $9.5 \%$ prevalence of B12 deficiency among type 2 diabetes patients on metformin. ${ }^{9}$ Using the sample size calculator for estimations with type I error probability and precision of
0.05 , the required sample size was $178 .{ }^{16}$ Sample size was augmented by $15 \%$ to take into account missing data. The final sample size was determined to be 205 .

\section{Statistical Analysis}

Descriptive analyses of all the demographic and outcome variables were performed. Results of the continuous variables are described with mean and standard deviation or median and interquartile range and results of categorical variables are described with frequency and percentage. Test of normality was used to determine the distribution of the outcome variables. Independent sample $t$-test was used for normally distributed variables, and MannWhitney $U$-test or Fisher Exact test for variables with a skewed distribution. Pearson Chi-Square test was used to determine association between categorical predictors variables and outcome variables. The variables with $p$-value $<0.2$ in the univariate analysis were included in the multivariate analysis. Multiple logistic regression analysis was performed to assess the independent predictive effect of the variables on the risk for vitamin B12 deficiency. All statistical analyses were performed using Statistical Package for Social Science (SPSS) Version 22.0. A $p$-value of less than 0.05 was considered significant.

\section{RESULTS}

Two hundred fifty-two patients with type $2 \mathrm{DM}$ were screened from two study centers. Forty-six patients were subsequently excluded. A total of 205 patients from two study centers were finally included in the study (Figure 1). Majority $(51.7 \%, \mathrm{n}=106)$ were recruited from a tertiary hospital while $48.3 \%(n=99)$ were from a health clinic.

Table 1 shows the baseline demographic data of our study population. A total of 79 (38.5\%) males and 126 (61.5\%) females were enrolled. Majority of the patients were of Malay race $(78 \%)$ while the remaining were non-Malay (15.6\% Chinese and $6.3 \%$ Indian). The median age of the

Screened for eligibility and met inclusion criteria $(n=252)$

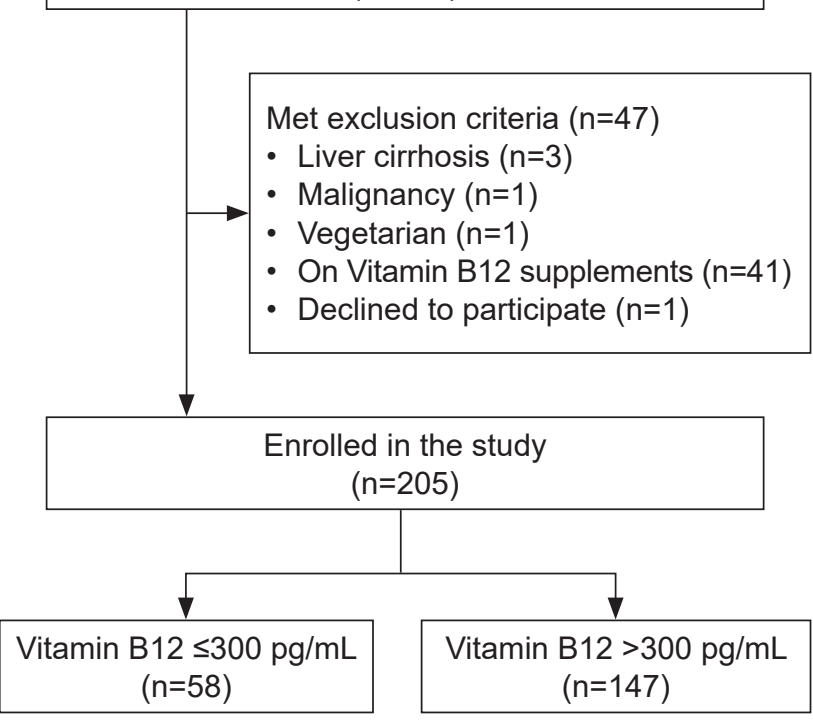

Figure 1. Study design summarizing sample recruitment. 
Table 2. Univariate logistic regression analysis

\begin{tabular}{|c|c|c|c|}
\hline & OR $^{\mathrm{a}}$ & $95 \% \mathrm{Cl}$ & $p$-value \\
\hline $\begin{array}{l}\text { Gender } \\
\text { Male } \\
\text { Female }\end{array}$ & $\begin{array}{c}1.18 \\
1\end{array}$ & $0.63-2.20$ & 0.60 \\
\hline $\begin{array}{l}\text { Race } \\
\text { Non-Malay } \\
\text { Malay }\end{array}$ & $\begin{array}{c}4.81 \\
1\end{array}$ & $2.39-9.70$ & $<0.01$ \\
\hline $\begin{array}{l}\text { Daily metformin dose (g/day) } \\
\quad>1000 \mathrm{mg} \\
\leq 1000 \mathrm{mg}\end{array}$ & $\begin{array}{c}1.57 \\
1 \\
\end{array}$ & $0.64-3.84$ & 0.33 \\
\hline $\begin{array}{l}\text { Metformin treatment duration } \\
>5 \text { years } \\
\leq 5 \text { years }\end{array}$ & $\begin{array}{c}2.27 \\
1 \\
\end{array}$ & $1.21-4.27$ & 0.01 \\
\hline $\begin{array}{r}\mathrm{HbA} 1 \mathrm{c}^{\mathrm{b}} \\
\quad \leq 7 \% \\
>7 \% \\
\end{array}$ & $\begin{array}{c}2.07 \\
1\end{array}$ & $0.94-4.56$ & 0.07 \\
\hline Age, yr & 1.03 & $1.00-1.06$ & 0.06 \\
\hline $\mathrm{BMI}^{\mathrm{c}}, \mathrm{kg} / \mathrm{m}^{2}$ & 1.02 & $0.98-1.07$ & 0.33 \\
\hline Diabetes duration, month & 1.00 & $1.00-1.01$ & 0.03 \\
\hline Smoking & 2.45 & $0.90-6.70$ & 0.08 \\
\hline Sulfonylurea & 1.01 & $0.55-1.87$ & 0.97 \\
\hline DPP-4d inhibitor & 0.83 & $0.26-2.70$ & 0.76 \\
\hline SGLT-2 ${ }^{\mathrm{e}}$ inhibitor & 1.27 & $0.11-14.30$ & 0.85 \\
\hline $\mathrm{PPI}^{\mathrm{f}}$ & 2.56 & $0.16-41.65$ & 0.51 \\
\hline $\mathrm{H}_{2} \mathrm{RA}^{\mathrm{g}}$ & 1.27 & $0.11-14.30$ & 0.85 \\
\hline $\begin{array}{l}\text { a OR, odds ratio } \\
\text { b }{ }^{\circ} \mathrm{HbA} 1 \mathrm{c} \text {, glycosylated hemogl } \\
{ }^{\mathrm{c}} \mathrm{BMI} \text {, body mass index } \\
\text { dDPP-4, dipeptidyl peptidase- } \\
\text { e } \mathrm{SGLT2} \text {, sodium glucose cotr } \\
\text { f } \mathrm{PPI} \text {, proton pump inhibitor } \\
{ }^{9} \mathrm{H}_{2} \mathrm{RA}, \mathrm{H}_{2} \text { receptor antagonis }\end{array}$ & & & \\
\hline
\end{tabular}

The prevalence of vitamin B12 deficiency in our study population is $28.3 \%$, which falls at the upper end of global prevalence. The worldwide prevalence of vitamin B12 deficiency among metformin users ranges between 4.3 to $30 \%{ }^{1,9,17,18}$ Vitamin B12 deficiency associated with metformin use is thought to occur due to vitamin B12 malabsorption. It is postulated that metformin interferes with the calcium-dependent membrane action responsible for vitamin B12-intrinsic factor absorption in the terminal ileum. ${ }^{6,719,20}$ The substantial prevalence of vitamin B12 deficiency in our population should prompt consideration for routine screening of this deficiency among metformintreated type $2 \mathrm{DM}$ patients.

Our study demonstrated that race and duration of metformin use were the most consistent associated factors with vitamin B12 deficiency among metformin users. This association remained evident after adjusting for potential confounding factors by multivariate analysis.

The most significant association was race. Non-Malay race was associated with an approximately four-fold increased risk for metformin-associated vitamin B12 deficiency even after adjusting for potential confounders $(p<0.001)$. A study conducted in Africa found that Black South African descent was a significant protective factor for vitamin B12 deficiency among metformin-treated patients. ${ }^{21}$ This was the first study to report ethnic differences in vitamin B12 levels among metformin-exposed type 2 DM patients. Higher levels of the vitamin binding proteins transcobalamin II and haptocorrin in black individuals have been described in South African settings, explaining their relatively elevated vitamin B12 levels. ${ }^{21}$ The difference in prevalence of vitamin B12 deficiency among different ethnic groups in Asia has not been studied. The currently utilized cut-off points and definitions of vitamin B12 deficiency do not consider the possible effects of ethnicity. ${ }^{21}$ Further research is needed to determine why Malay ethnicity seemed protective against metformin-associated vitamin B12 deficiency.

Duration of metformin use of more than five years conferred a greater than two-fold increased risk for vitamin B12 deficiency $(p=0.049)$ in our population. Several studies have shown a significant positive association between duration of metformin use and vitamin B12 deficiency. ${ }^{3,9,17,22}$ In a large-scale study among Koreans ( $\mathrm{n}=799)$, daily metformin dosage and treatment duration were the most consistent risk factors for vitamin B12 deficiency. ${ }^{9}$ Secondary analysis from the Diabetes Prevention Program Outcomes Study (DPPOS) showed that 13 years after randomization, there was a $13 \%$ increased risk for vitamin B12 deficiency per year of total metformin use. ${ }^{17}$ The results of our study echo these findings of increased risk for vitamin B12 deficiency with longer duration of metformin use.

Age, sex, body mass index, smoking, duration of diabetes and $\mathrm{HbA1c}$ levels did not show a statistically significant association with vitamin B12 deficiency in our population. There was no significant association between vitamin B12 deficiency and the use of other antidiabetes medications (Table 2).

Previous studies have linked vitamin B12 deficiency with the use of PPI and $\mathrm{H}_{2} \mathrm{RA}$ among metformintreated patients. These observations were supported by the concept that gastric acidity is vital for vitamin B12 absorption, and that PPI and $\mathrm{H}_{2} \mathrm{RA}$ result in reduction in acid discharge by gastric parietal cells. ${ }^{20,23,24}$ However, this finding was controversial. ${ }^{1,11}$ Our study did not find a significant association between use of PPI or $\mathrm{H}_{2} \mathrm{RA}$ and vitamin B12 deficiency. This could be attributed to the very small number of patients in our study who were on PPI or $\mathrm{H}_{2} \mathrm{RA}(\mathrm{n}=5)$.

Vitamin B12 deficiency is clinically important as it can cause anemia, bone marrow failure, peripheral neuropathy and cognitive impairment. ${ }^{8,9,25}$ Neuropathy secondary to metformin-associated vitamin B12 deficiency may be mistaken for peripheral neuropathy secondary to diabetes-associated microvascular complications, as

Table 3. Multiple logistic regression analysis

\begin{tabular}{lcccc}
\hline & Adjusted OR & $\mathbf{9 5 \%} \mathbf{C l}$ & $\boldsymbol{P}$ & Cov and Snell R square \\
\hline Non-Malay race & 3.86 & $1.836-8.104$ & $<0.001$ & 0.13 \\
Duration of metformin use $>5$ years & 2.06 & $1.003-4.227$ & 0.049 & 0.19 \\
Non-smoker & 0.36 & $0.120-1.059$ & 0.063 & \\
$\mathrm{HbA} 1 \mathrm{c}^{\mathrm{b}} \leq 7 \%$ & 2.32 & $0.934-5.751$ & 0.070 & \\
Constant & 3.24 & & 0.056 & \\
\hline
\end{tabular}


both diseases can result in reduced vibration sense and diminished proprioception. ${ }^{8,26}$ There is no definitive clinical or electrophysiological test that can differentiate diabetic peripheral neuropathy from vitamin B12associated neuropathy. ${ }^{8}$ This may lead to inappropriate use of tricyclic antidepressants and anticonvulsants to manage symptoms. ${ }^{8,27,28}$

Recognition of metformin-associated vitamin B12 deficiency is imperative as it is potentially treatable and reversible. Multivitamin use seemed to protect type $2 \mathrm{DM}$ patients from B12 deficiency. ${ }^{18}$ Randomized trials among adults taking supplemental vitamin B12 doses as low as 6 to 9 mcg daily show higher serum B12 levels compared with placebo..$^{29,30}$

We regard the prevalence of vitamin B12 deficiency of $28.3 \%$ in our study population as a substantial percentage, as it affects over a quarter of the type 2 DM patients who are on metformin. This provides a valuable manual for clinicians to consider testing for vitamin B12 levels especially among type $2 \mathrm{DM}$ patients who are of non-Malay race and who have been on metformin for more than five years. Although the clinical implication of our findings has not been demonstrated in this study, the potential complications of vitamin B12 deficiency has been well documented in literature.

Our study had several limitations. It was conducted in two centers from a single district, which may not be representative of the entire Malaysian population. We were unable to measure serum homocysteine and serum methylmalonic acid, early markers of vitamin B12 deficiency, as this was cost-prohibitive. The study was not sufficiently powered for some of the factors that were evaluated as an association with B12 deficiency in our population. We did not include a detailed dietary history which could be a potential contributing factor to low vitamin B12 levels.

\section{CONCLUSION}

Given the mounting evidence associating metformin exposure with low vitamin B12 levels, assessment of serum vitamin B12 levels among metformin-treated patients should be incorporated into routine clinical practice. According to the 2019 National Health and Morbidity Survey (NHMS), the prevalence of type 2 DM in Malaysia is $18.3 \%$ among adults above the age of $18 .{ }^{31}$ Metformin is widely recommended as a first line agent in the treatment of type $2 \mathrm{DM}$. Our study supports evidence that use of metformin is indeed associated with vitamin B12 deficiency and the prevalence of this association in our study population is significant. Testing for vitamin B12 deficiency among metformin-treated type 2 DM patients should be strongly considered especially among patients who are of non-Malay race and those who have been on metformin for more than five years.

\section{Acknowledgments}

The authors thank the Malaysian Endocrine and Metabolic Society (MEMS) for funding the research. They also extend their gratitude to Dr. Wan Hasmawati Binti Wan Ismail, family medicine physician, and the staff of Klinik Kesihatan Paya Besar, for accommodating their research.
Statement of Authorship

All authors certified fulfillment of ICMJE authorship criteria.

\section{Author Disclosure}

The authors declared no conflicts of interest.

\section{Funding Source}

The Malaysian Endocrine and Metabolic Society (MEMS) funded this research.

\section{References}

1. Nervo M, Lubini A, Raimundo FV, et al. Vitamin B12 in metformintreated diabetic patients: A cross-sectional study in Brazil. Rev Assoc Med Bras (1992). 2011;57(1):46-9. PMID: 21390459.

2. Tomkin GH, Hadden DR, Weaver JA, Montgomery DAD. Vitamin B12 status of patients on long-term metformin therapy. Br Med J 1971;2(5763):685-7. PMID: 5556053. PMCID: PMC1796258. https://doi. org/10.1136/bmj.2.5763.685.

3. Reinstatler L, Qi YP, Williamson RS, Garn JV, Oakley GPJ. Association of biochemical B12 deficiency with metformin therapy and vitamin B12 supplements: The National Health and Nutrition Examination Survey, 1999-2006. Diabetes Care. 2012;35(2):327-33. PMID: 22179958. PMCID: PMC3263877. https://doi.org/10.2337/dc11-1582.

4. Romero JMC, Lozano JMR. Vitamin B(12) in type 2 diabetic patients treated with metformin. Endocrinol Nutr. 2012;59(8):487-90. PMID: 22981397. https://doi.org/10.1016/j.endonu.2012.06.005.

5. Pongchaidecha M, Srikusalanukul V, Chattananon A, Tanjariyaporn S. Effect of metformin on plasma homocysteine, vitamin B12 and folic acid: A cross-sectional study in patients with type 2 diabetes mellitus. J Med Assoc Thai. 2004;87(7):780-7. PMID: 15521233.

6. Berchtold P, Bolli P, Arbenz U, Keiser G. Disturbance of intestinal absorption following metformin therapy (observations on the mode of action of biguanides). Diabetologia. 1969;5(6):405-12. PMID: 5372893. https://doi.org/10.1007/BF00427979.

7. Caspary WF, Zavada I, Reimold W, Deuticke U, Emrich D, Willms B. Alteration of bile acid metabolism and vitamin-B12-absorption in diabetics on biguanides. Diabetologia. 1977;13(3):187-93. PMID: 873086. https://doi.org/10.1007/BF01219698.

8. Bell DSH. Metformin-induced vitamin B12 deficiency presenting as a peripheral neuropathy. South Med J. 2010;103(3):265-7. PMID 20134380. https://doi.org/10.1097/SMJ.0b013e3181ce0e4d.

9. Ko SH, Ko SH, Ahn YB, et al. Association of vitamin B12 deficiency and metformin use in patients with type 2 diabetes. J Korean Med Sci. 2014;29(7):965-72. PMID: 25045229. PMCID: PMC4101785. https://doi. org $/ 10.3346 / \mathrm{jkms} .2014 .29 .7 .965$.

10. Shaw LM, Strømme JH, London JL, Theodorsen L. International Federation of Clinical Chemistry (IFCC), Scientific Committee, Analytical Section. IFCC methods for the measurement of catalytic concentration of enzymes. Part 4. IFCC method for gammaglutamyltransferase [(gamma-glutamyl)-peptide: amino acid gamma-glutamyltransferase, EC 2.3.2.2]. J Clin Chem Clin Biochem. 1983;21(10);633-46. PMID: 6139407.

11. Liu Q, Li S, Quan H, Li J. Vitamin B12 status in metformin treated patients: Systematic review. PLoS One. 2014; 9(6):e100379. PMID 24959880. PMCID: PMC4069007. https://doi.org/10.1371/journal. pone. 0100379

12. Khan A, Shafiq I, Shah MH. Prevalence of vitamin B12 deficiency in patients with type 2 diabetes mellitus on metformin: A study from Khyber Pakhtunkhwa. Cureus. 2017:9(8):e1577. PMID: 29057189. PMCID: PMC5647126. https://doi.org/10.7759/cureus.1577.

13. Toh BH, van Driel IR, Gleeson PA. Pernicious anemia. N Engl J Med. 1997;337(20):1441-8. PMID: 9358143. https://doi.org/10.1056/ NEJM199711133372007.

14. Lindenbaum J. Folate and vitamin B12 deficiencies in alcoholism. Semin. Hematol. 1980;17(2):119-29. PMID: 6990497.

15. Long AN, Atwell CL, Yoo W, Solomon SS. Vitamin B(12) deficiency associated with concomitant metformin and proton pump inhibitor use. Diabetes Care. 2012;35(12):e84. PMID: 23173145. PMCID: PMC3507616. https://doi.org/10.2337/dc12-0980.

16. Daniel WW. Biostatistics: A foundation for analysis in the health sciences. 7th ed. New York: John Wiley \& Sons, 1999.

17. Aroda VR, Edelstein SL, Goldberg RB, et al. Long-term metformin use and vitamin B12 deficiency in the Diabetes Prevention Program Outcomes Study. J Clin Endocrinol Metab. 2016;101(4):1754-61. PMID: 26900641. PMCID: PMC4880159. https://doi.org/10.1210/jc.2015-3754.

18. Pflipsen MC, Oh RC, Saguil A, et al. The prevalence of vitamin B(12) deficiency in patients with type 2 diabetes: A cross-sectional study. J Am Board Fam Med. 2009;22(5):528-34. PMID: 19734399. https://doi/ org/10.3122/jabfm.2009.05.090044.

19. Berchtold P, Dahlqvist A, Gustafson A, Asp NG. Effects of a biguanide (metformin) on vitamin B12 and folic acid absorption and intestinal 
enzyme activities. Scand J Gastroenterol. 1971;6(8):751-4. PMID 5139118. https://doi.org/10.3109/00365527109179948

20. Bauman WA, Shaw S, Jayatilleke E, Spungen AM, Herbert V. Increased intake of calcium reverses vitamin B12 malabsorption induced by metformin. Diabetes Care. 2000;23(9):1227-31. PMID: 10977010. https:// doi.org/10.2337/diacare.23.9.1227.

21. Fernandes-Costa F, Metz J. A comparison of serum transcobalamin levels in white and black subjects. Am J Clin Nutr. 1982;35(1):83-6. PMID: 7064880. https://doi.org/10.1093/ajcn/35.1.83.

22. Ahmed MA, Muntingh G, Rheeder P. Vitamin B12 deficiency in metformin-treated type 2 diabetes patients, prevalence and association with peripheral neuropathy. BMC Pharmacol Toxicol. 2016:17:44. PMID: 27716423. PMCID: PMC5054613. https://doi.org/10.1186/ s40360-016-0088-3.

23. Valuck RJ, Ruscin JM. A case-control study on adverse effects: H2 blocker or proton pump inhibitor use and risk of vitamin B12 deficiency in older adults. J Clin Epidemiol. 2004;57(4):422-8. PMID: 15135846. https://doi.org/10.1016/j.jclinepi.2003.08.015.

24. Ruscin JM, Page RL 2nd, Valuck RJ. Vitamin B(12) deficiency associated with histamine(2)-receptor antagonists and a proton-pump inhibitor. Ann Pharmacother. 2002;36(5):812-6. PMID: 11978157. https://doi. org/10.1345/aph.10325.

25. Hin $\mathrm{H}$, Clarke R, Sherliker P, et al. Clinical relevance of low serum vitamin B12 concentrations in older people: The Banbury B12 study. Age Ageing. 2006;35(4):416-22. PMID: 16709605. https://doi. org/10.1093/ageing/afl033.
26. Lindenbaum J, Healton EB, Savage DG, et al. Neuropsychiatric disorders caused by cobalamin deficiency in the absence of anemia or macrocytosis. N Engl J Med. 1988; 318(26):1720-8. PMID: 3374544. https://doi.org/10.1056/NEJM198806303182604.

27. Naha K, Dasari S, Vivek G, Prabhu M. Vitamin B12 deficiency: An unusual cause for recurrent generalised seizures with pancytopaenia BMJ Case Reports. 2012;10.1136/bcr-2012-006632. PMID: 22948998 PMCID: PMC4543758. https://doi.org/10.1136/bcr-2012-006632.

28. Durand C, Mary S, Brazo P, Dollfus S. Psychiatric manifestations of vitamin B12 deficiency: A case report. Encephale. 2003;29(6):560-5. PMID: 15029091.

29. McKay DL, Perrone G, Rasmussen H, Dallal G, Blumberg JB. Multivitamin/mineral supplementation improves plasma B-vitamin status and homocysteine concentration in healthy older adults consuming a folate-fortified diet. J Nutr. 2000;130(12):3090-6. PMID: 11110875. https://doi.org/10.1093/jn/130.12.3090.

30. Wolters M, HermannS, Hahn A. Effect of multivitamin supplementation on the homocysteine and methylmalonic acid blood concentrations in women over the age of 60 years. Eur J Nutr. 2005:44(3):183-92. PMID: 15309436. https://doi.org/10.1007/s00394-004-0510-2.

31. Institute for Public Health 2020. National Health and Morbidity Survey (NHMS) 2019.: Non-communicable diseases, healthcare demand, and health literacy - Key Findings. http://iku.moh.gov.my/images/IKU/ Document/REPORT/NHMS2019/Infographic_Booklet_NHMS_2019English.pdf.

Authors are required to accomplish, sign and submit scanned copies of the JAFES Author Form consisting of: (1) Authorship Certification, that authors contributed substantially to the work, that the manuscript has been read and approved by all authors, and that the requirements for authorship have been met by each author; (2) the Author Declaration, that the article represents original material that is not being considered for publication or has not been published or accepted for publication elsewhere, that the article does not infringe or violate any copyrights or intellectual property rights, and that no references have been made to predatory/ suspected predatory journals; (3) the Author Contribution Disclosure, which lists the specific contributions of authors; and (4) the Author Publishing Agreement which retains author copyright, grants publishing and distribution rights to JAFES, and allows JAFES to apply and enforce an Attribution-Non-Commercia Creative Commons user license. Authors are also required to accomplish, sign, and submit the signed ICMJE form for Disclosure of Potential Conflicts of Interest. For original articles, authors are required to submit a scanned copy of the Ethics Review Approval of their research as well as registration in trial registries as appropriate. For manuscripts reporting data from studies involving animals, authors are required to submit a scanned copy of the Institutional Animal Care and Use Committee approval. For Case Reports or Series, and Images in Endocrinology, consent forms, are required for the publication of information about patients, otherwise, appropriate ethical clearance has been obtained from the institutional review board. Articles and any other material published in the JAFES represent the work of the author(s) and should not be construed to reflect the opinions of the Editors or the Publisher.

\section{Appendix 1. Association of Vitamin B12 deficiency and Metformin in Type 2 Diabetes Mellitus}

\section{Data Collection Sheet}

\begin{tabular}{|l|l|l|l|}
\hline Date & & Centre & \\
\hline Name of Investigator & & \\
\hline
\end{tabular}

\section{Subject Information}

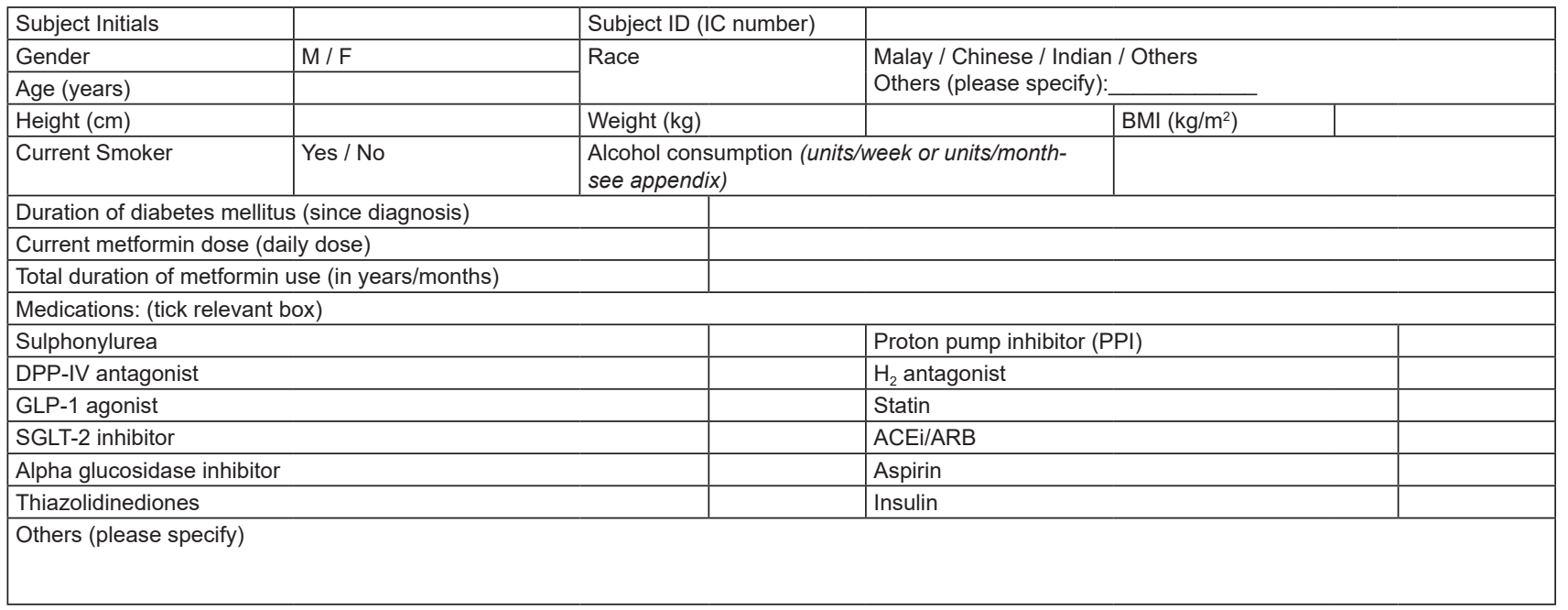

\section{Lab Investigations}

\begin{tabular}{|l|l|l|}
\hline \multicolumn{1}{|c|}{ Test } & Value & \multicolumn{1}{|c|}{ Date } \\
\hline Vitamin B12 level $(\mathrm{pg} / \mathrm{mL})$ & & \\
\hline Fasting Blood Sugar (mmol/L) & & \\
\hline HbA1c (\%) *(latest available value) & & \\
\hline
\end{tabular}

